\title{
ALCOHOL TOLERANCE AND ALCOHOL UTILISATION IN DROSOPHILA: PARTIAL INDEPENDENCE OF TWO ADAPTIVE TRAITS
}

\author{
JEANNINE VAN HERREWEGE and J. R. DAVID* \\ Laboratoire d'Entomologie expérimentale et de Génétique, Université Claude Bernard, 69621 \\ Villeurbanne, France
}

Received 27.ix.79

\begin{abstract}
SUMMARY
Three natural populations of $D$. melanogaster with different ethanol tolerance, and a population of $D$. simulans were successfully selected for an increased capacity to withstand alcohol. Alcohol utilisation, measured by the increase of life duration in the presence of low concentrations of alcohol, was clearly improved only in two cases. Alcohol tolerance and utilisation, two physiological traits that both depend on the presence of an active ADH, are thus controlled, at least partly, by different genetic mechanisms. In Drosophila species breeding on fermenting fruits or in wine cellars, both traits may be under the control of natural selection.
\end{abstract}

\section{INTRODUCTION}

THE use of resources containing a large amount of ethanol is typical of Drosophila melanogaster. This peculiarity is accompanied by a high ethanol tolerance for which the enzyme alcohol dehydrogenase (ADH) is necessary (see David, 1977, for a review). Two hypotheses have been considered for explaining this observation. It has often been assumed that alcohol tolerance is simply a detoxification process selected to allow larvae and adults to feed on the yeasts responsible for alcoholic fermentation (Clarke, 1975); however Drosophila adults are able to use ethanol as a food (Van Herrewege and David, 1974, 1978; Libion-Mannaert et al., 1976) and the detoxification process seems to involve its conversion into acetate and its further transformation in " energy metabolism" (David et al., 1978; Deltombe-Lietaert et al., 1979). Ethanol use could therefore be the primary target of natural selection, being responsible for the high $\mathrm{ADH}$ activity found in $D$. melanogaster.

Recently another Drosophila species (D. lebanonensis) which lives in Spanish wine cellars has been found to be much more tolerant to ethanol than $D$. melanogaster since the "lethal concentration 50" (concentration which kills half the adults after two days of treatment) was 28 per cent against 17 per cent in D. melanogaster (David et al., 1979). Obviously such a high tolerance is not needed since ethanol concentration in fermented substrates does not exceed 12-13 per cent. D. lebanonensis also appears capable of a much more efficient use of alcohol than D. melanogaster and it has been suggested that this

* Present address: Laboratoire de Biologie et Génétique évolutives, GNRS, 91190, Gif sur Yvette, France. 
high tolerance could be a by-product of a selection for improving alcohol use.

Trying to choose between the two hypotheses led us to look for a correlation between alcohol tolerance and alcohol utilisation. D. melanogaster is well suited to such an analysis because great differences in alcohol sensitivity are found in natural populations, varying with latitude (David and Bocquet, 1975). Starting from three different populations, lines were selected for alcohol tolerance and a significant increase in resistance was obtained in all cases (David et al., 1977). A sibling species, $D$. simulans, which is much more alcohol sensitive, was also selected and included in the present study. The capacity to use ethanol was measured in the four selected lines and compared to the values found in the initial, non-selected populations.

The following results show that only a loose correlation exists between ethanol tolerance and the capacity for metabolic use, and that increasing the tolerance by selection is not accompanied in all cases by a more effective use. These two physiological properties therefore involve genetic mechanisms which are partly independent.

\section{Material and Methods}

Selection for alcohol tolerance was described in a previous paper (David et al., 1977) and the data will be summarised briefly. In Drosophila melanogaster, three different populations of various origins were selected for increased ethanol tolerance. In an African strain (Brazzaville) the initial tolerance of 6.5 per cent of alcohol was increased to 18 per cent. In a tropical American strain (Puerto Asis, Columbia) tolerance rose from 10 to 24 per cent, and in a French strain (Colmar) from 16 to 28 per cent. In a D. simulans strain from Teneriffe tolerance was increased from 4 to 6.5 per cent.

Drosophila melangaster is polymorphic for two alleles of $\mathrm{ADH}$ : the fast allele $(F)$ has an enzymatic activity about twice that of the slow allele $(S)$ (David, 1977). In the Colmar population the initial population was " $F$ " homozygous. The two others were segregating for $S$ and $F$ and the selection resulted in the elimination of $S$. D. simulans is known to be monomorphic at the locus.

Tests of ethanol use were made on adults in air-tight plastic vials according to a previously described technique (Van Herrewege and David, 1978). Groups of newly emerged adults were placed in these vials in the presence of a water-ethanol solution absorbed in cellulose wool. Dead flies were counted twice a day and the average longevity calculated. Ethanol use was measured by the increase in the length of life due to ethanol. Various concentrations, varying from 0 to 24 per cent were used. For each concentration, the number of adults studied ranged between 40 and 60 , and the sexes were averaged.

\section{Results}

Variation of adult longevity as a function of alcohol concentrations is given in fig. 1. All response curves have the same general shape, as previously described (Van Herrewege and David, 1978). Without alcohol or any other food, adults die of starvation after exhausting the reserves accumulated during the larval stage (David et al., 1975). If a small amount of alcohol is 

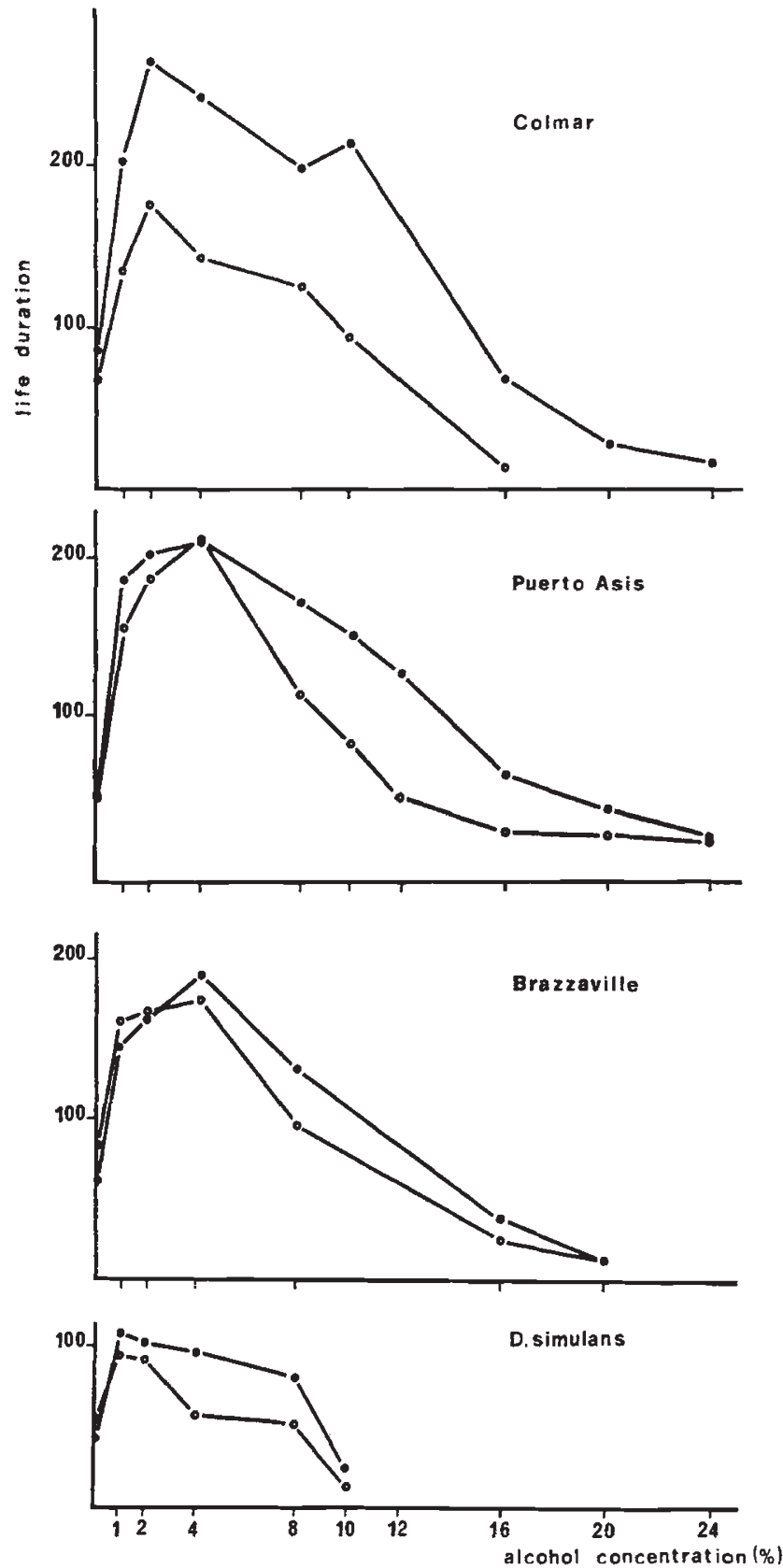

FIG. 1.- Life duration of adults as a function of ethanol concentration in three populations of Drosophila melanogaster (Colmar, Puerto-Asis and Brazzaville) and one population of D. simulans.

O: unselected population;

: strain selected for increased ethanol tolerance. 
added, a significant increase in the duration of life is observed. The optimum concentration seems to be 1 per cent for $D$. simulans and 2 or 4 per cent for $D$. melanogaster. Above the optimum concentration, the duration of life decreases progressively because the toxic effects of ethanol overcome its beneficial ones.

In spite of the overall similarity of the curves, significant differences are observed either between the different populations studied or between unselected and selected strains of each population. In order to summarise these differences, we have compared the alcohol tolerance of each strain with its life duration for various ethanol concentrations. Results are presented in fig. 2.

In the absence of ethanol, the duration of life (fig. 2A) of the various strains varied between 44 and 83 hours. In a previous comparison of the selected and unselected Colmar strains (David and Bocquet, 1977) it was noted that most morphological and physiological traits did not change, the main exception being an increase of resistance to starvation in the selected strain. It can be seen here, by comparing four such couples, that this increase is not a general rule. In one strain (Puerto Asis) the length of life was not modified. In the two others (Brazzaville and $D$. simulans) a significant reduction was observed.

Changes in the duration of the life of adults in the absence of alcohol are therefore not related to one physiological modification brought about by the ethanol selection. These changes may simply reflect a random drift occurring during selection as a by-product of inbreeding. Such variations, however, complicate the analysis of ethanol use, and it has seemed better, in comparing the metabolic capacities of selected and non-selected lines, to consider the differences in the length of life between flies receiving ethanol and controls receiving no ethanol.

The results obtained with a small, non-toxic concentration of ethanol ( 1 per cent) are given in fig. 2B. Again, we see divergent responses among the strains. In three cases, selection improved alcohol utilisation while the Brazzaville population showed no significant effect. Analysis of the curves shown in fig. 1 extend this conclusion. A clear improvement in ethanol use after selection was obtained only in the Colmar population, and to a lesser degree in $D$. simulans. In both the Brazzaville and Puerto Asis populations, increasing ethanol tolerance by selection did not result in a better use of low concentrations of alcohol.

On the other hand, all the selected strains survived better when subjected to high ethanol concentrations. As an example, the results obtained with 8 per cent alcohol are given in fig. $2 \mathrm{C}$ and show a clear correlation between tolerance and utilisation. Such a conclusion is by no means unexpected: increasing the alcohol tolerance makes the flies less sensitive to the noxious

F1G. 2.-Effects of selection for increasing ethanol on:

A: survival of adults in absence of alcohol and any other food;

B: capacity for using a small concentration of alcohol ( 1 per cent) as a food;

G: capacity for using a concentration of 8 per cent of alcohol;

Abscissa: ethanol tolerance (expressed by the LC 50 on adults in percent ethanol;

Ordinate: A: life duration in hours; $\mathrm{B}$ and $\mathrm{C}$ : increase of life duration over the controls receiving no alcohol; $:$ : unselected population; $\mathbf{D}$ : selected strain; geographic origin: G: Colmar; P.A.: Puerto Asis; B: Brazzaville (all D. melanogaster); D.s.: D. simulans from Teneriffe. 


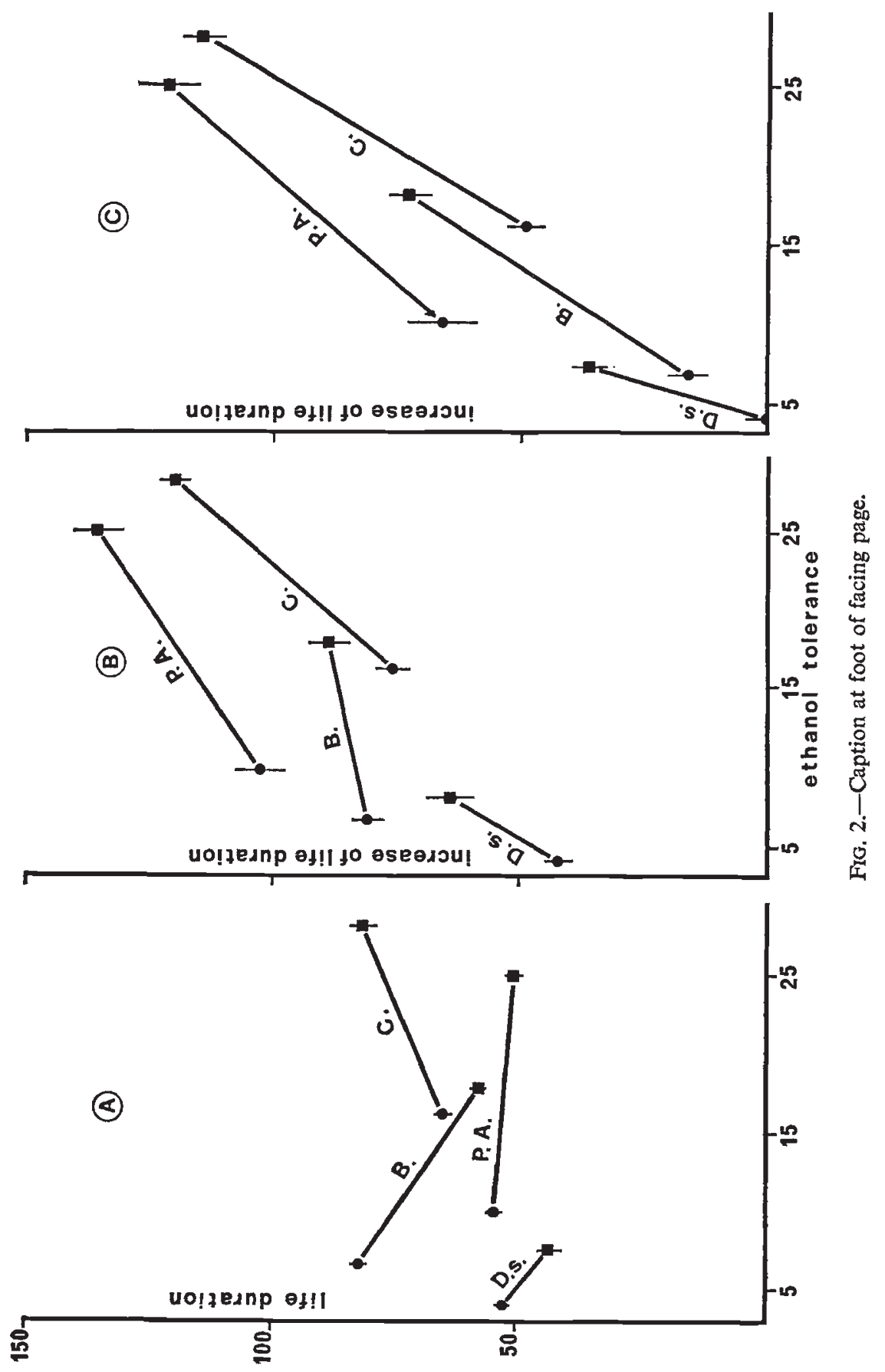


effects of excessive concentrations. Another way of describing the same phenomenon is to consider the alcohol concentration at which beneficial effects just balance the noxious ones, that is the concentration for which the duration of life is identical to that of control, untreated flies. From fig. 1, these values are estimated respectively for unselected and selected lines: 8 and 9 per cent for $D$. simulans, 10 and 15 per cent for $D$. melanogaster Brazzaville, 12 and 18 per cent for Puerto Asis, 12 and 16 per cent for Colmar.

\section{Discussion}

In all cases, increasing ethanol tolerance by selection improved the capacity to use high concentrations of alcohol: all selected strains appeared less sensitive to the noxious effects of excess ethanol. The presence of an active ADH is necessary for ethanol detoxification (David et al., 1976). Ethanol tolerance is positively correlated with the enzymatic activity found in the fly (Oakeshott, 1976; Kamping and Van Delden, 1978). Analysis of the Colmar selected strain revealed an increase in its $\mathrm{ADH}$ activity (McDonald et al., 1977). Finally, it is known that D. simulans, which is ethanol sensitive, has also a lower ADH activity than D. melanogaster (Pipkin and Hewitt, 1972). All these observations are consistent and we can assume therefore that fig. $2 \mathrm{C}$ expresses a causal relationship between $\mathrm{ADH}$ activity and the ability to metabolise high concentrations of ethanol.

The relationship between $\mathrm{ADH}$ activity and the physiology of the fly is not, however, a simple one. An environmental control of the amount of $\mathrm{ADH}$ in adults has been recently shown (Clarke et al., 1979). Several authors have argued that survival on ethanol food and $\mathrm{ADH}$ activity are not related by direct causality (McKenzie and Parsons, 1974; BijlsmaMeeles, 1979). A possible role of Drosophila catalase in ethanol metabolism has been recently suggested (Deltombe-Lietaert et al., 1979). Our results increase the complexity of the problem by showing a genetic independence between ethanol tolerance and the capacity to use small concentrations of the alcohol. We know that ADH is a crucial enzyme for alcohol use since a null mutant was found unable to use a low, non-toxic, concentration of ethanol (David et al., 1978). Fig. 2B shows, however, that the unselected populations of Brazzaville and Puerto-Asis, which were fairly sensitive to ethanol, were capable of a better use than the tolerant Colmar population. Moreover, the two tropical populations did not improve their capacity to use ethanol when submitted to selection for increased tolerance, while the Colmar population did so.

As far as we know, both the detoxification and the use of ethanol involve its conversion into acetate (David et al., 1976, 1978; Deltombe-Lietaert et al., 1979) but this transformation implies at least two independent enzymatic steps. Moreover the capacity of transforming acetate into acetylcoenzyme A could vary from strain to strain, as could the capacity of using this last product for energy production. Other possibilities of divergence between strains or species also exist, for example in their behaviour in the presence of ethanol.

It is therefore not surprising to find that ethanol tolerance and use are two different traits that can be genetically independent. The adaptation of Drosophila to ethanol-containing resources may mainly correspond either to 
a necessity for detoxification or to a need for nutrition. Comparison of natural populations using different resources, or of species having different habitats, should help us to understand which of these two processes has been the main target of natural selection.

Acknowledgment.-We thank Prof. R. Grantham for critically reading the manuscript.

\section{REFERENCES}

GLARKE, B. 1975. The contribution of ecological genetics to evolutionary theory: detecting the direct effect of natural selection on particular polymorphic loci. Genetics, 79, 101113.

CLARKE, B., CAMfield, R. G., GAlvin, A. M., AND PITTS, C. R. 1979. Environmental factors affecting the quantity of alcohol dehydrogenase in Drosophila melanogaster. Nature, 280, $517-518$.

DAVID, J. R. 1977. Signification d'un polymorphisme enzymatique: la déshydrogenase alcoolique chez Drosophila melanogaster. Ann. Biol., 16, 451-472.

DAVID, J. R., AND BOCQUET, C. 1975. Similarities and differences in the latitudinal adaptation of two Drosophila sibling species. Nature, 257, 588-590.

DAVID, J. R., AND BOCQUET, c. 1977. Genetic tolerance to ethanol in Drosophila melanogaster: increase by selection and analysis of correlated responses. Genetica, 47, 43-48.

DAVID, J. R., BOCQUET, C., ARENS, M. F., AND FOUILLET, P. 1976. Biological role of alcohol dehydrogenase in the tolerance of Drosophila melanogaster to aliphatic alcohols: utilization of an ADH-null mutant. Biochem. Genet., 14, 989-997.

DAVID, J. R., BOcQUET, C., FOUILLET, P., AND M. F. ARENs. 1977. Tolérance génétique à l'alcool chez Drosophila: comparaison des effets de la sélection chez $D$. melanogaster et D. simulans. C.R. Acad. Sci. Paris, 285, 405-408.

DAVID, J. R., BOCQUET, C., VAN HERREWEGE, J., FOUILLET, P., AND ARENS, M. F. 1978. Alcohol metabolism in Drosophila melanogaster: uselessness of the most active aldehyde oxidase produced by the Aldox locus. Biochem. Genet., 16, 203-211.

DAVID, J. R., COHET, Y., AND FOUILLET, P. 1975. La résistance à l'inanition chez les Insectes: importance de la quantité des réserves lipidiques chez les adultes de Drosophila melanogaster. C.R. Acad. Sci. Paris, 280, 2571-2574.

DAVID, J. R., VAN HERREWEGE, J., MONClus, M., AND PREVOSTI, A. 1979. High ethanol tolerance in two distantly related Drosophila species: a probable case of recent convergent adaptation. Comp. Biochem. Physiol., 63, 53-56.

DELTOMBE-LIETAERT, M. C., DELCOUR, J., LENELLE-MONFORT, N., AND ELENS, A. 1979. Ethanol metabolism in Drosophila melanogaster. Experientia, 35, 579-581.

KAMPING, A., AND VAN DELDEN, w. 1978. Alcohol dehydrogenase polymorphism in populations of Drosophila melanogaster. II. Relation between $\mathrm{ADH}$ activity and adult mortality. Biochem. Genet., 16, 541-551.

Libion-MANNAERT, M., Delcour, J., Deltombe-lietaert, N., LeNelle-MONTFORT, N., AND ELENS, A. 1976. Ethanol as a food for Drosophila melanogaster: influence of the ebony gene. Experientia, 32, 22-23.

MCDONALD, J. F., CHAMBERS, G. K., DAVID, J. R., AND AYALA, F. J. 1977. Adaptive response due to changes in gene regulation: a study with Drasophila. Proc. Natl. Acad. Sci., U.S.A., $74,4562-4566$.

MCKENZIE, J. A., AND PARSONS, P. A. 1974. Microdifferentiation in a natural population of Drosophila melanogaster to alcohol in the environment. Genetics, 77, 385-394.

oAKEshotT, J. G. 1976. Selection at the alcohol dehydrogenase locus in Drosophila melanogaster imposed by environmental ethanol. Genet. Res., 26, 265-274.

PIPKIN, S. B., AND HEWITT, N. E. 1972. Variation of alcohol dehydrogenase levels in Drosophila species hybrids. 7. Heredity, 63, 267-270.

VAN HERREWEGE, J., AND DAVID, J. R. 1974. Utilisation de l'alcool éthylique dans le métabolisme énergétique d'un insecte: influence sur la durée de survie des adultes de Drosophila melanogaster. C.R. Acad. Sci. Paris, 279, 335-338.

VAN HERREWEGE, J., AND DAVID, J. 1978. Feeding an insect through its respiration: assimilation of alcohol vapors by Drosophila melanogaster adults. Experientia, 34, 163-164. 